\title{
REVISED TRAVEL TIMES IN SOUTHERN CALIFORNIA*
}

\author{
By B. Gutenderg
}

\begin{abstract}
Discrepancides of up to 20 per cent between wave velocities calculated from blast records in southern California and those found from earthquakes necessitate a reinterpretation of seismograms of all near-by shocks and a revision of travel-time curves. A combination of findings for $\mathrm{S}-\mathrm{P}$ intervals as a function of distance in southern California earthquake records with the ratio of mean interval velocities for $\mathrm{P}$ and $\mathrm{S}$ waves shows (without assumption of origin times) that the mean velocities of the two waves between the source and the surface are about 6.35 and $3.67 \mathrm{~km} /$ sec., respectively. This agrees with the results found from blast records. Most revised origin times are between $3 / 4$ sec. and $11 / 2$ sec. later than those found previously from $\overline{\mathbf{P}}$. The method applied here removes the difference in origin time for longitudinal and transverse waves which was found formerly for earthquakes. Travel-time curves of various phases are revised and reinterpreted. The change in amplitudes with distance of several wave types is discussed.
\end{abstract}

DATA from blasts in southern California (Gutenberg, 1950a) $\dagger$ indicate that the velocity of longitudinal waves increases from about 5.8 to about $6.5 \mathrm{~km} / \mathrm{sec}$. at a depth of approximately $6 \mathrm{~km}$. and to about $6.9 \mathrm{~km} / \mathrm{sec}$. at a depth of between 10 and $12 \mathrm{~km}$. This disagrees with the values calculated from earthquake records on the assumption that $\overline{\mathrm{P}}$ and $\overline{\mathrm{S}}$ at distances greater than about $80 \mathrm{~km}$. are direct body waves. It has been suggested therefore (Gutenberg, $1950 b$ ) that this assumption is incorrect.

New calculations are based on records of fifty earthquakes discussed previously (Gutenberg, 1943, 1944a) and on records of earthquakes in 1949 which were investigated by C. F. Richter (1950). The locations of epicenters of the earlier shocks (Gutenberg, 1944a, p. 502) are only slightly changed as a consequence of the new values for the wave velocities. It can be assumed that the locations of the old epicenters are as accurate as they were considered to be in the earlier discussion of these shocks.

Time differences $\mathrm{S}$ - P measured on seismograms corresponding to distances up to about $120 \mathrm{~km}$. are plotted as a function of distance in fig. 1, a). ${ }^{1}$ The agreement between the observations is good.

The use of the data in figure 1, $a$ to find quantities related to the structure of the earth's crust in the region involved has to be based on a minimum number of assumptions. To a first approximation it may be assumed that the velocities $V$ of longitudinal waves and $v$ of transverse waves between the source of the earthquake (supposed to be a point at the depth $h$ ) and the surface of the earth are constant. In this case the travel-time difference $d$ of $\mathrm{S}-\mathrm{P}$ at the

\footnotetext{
* Manuscript received for publication April 5, 1950.

$\dagger$ For bibliographical reference see p. 163 below.

i The figures were drafted by Mr. John M. Nordquist.
} 

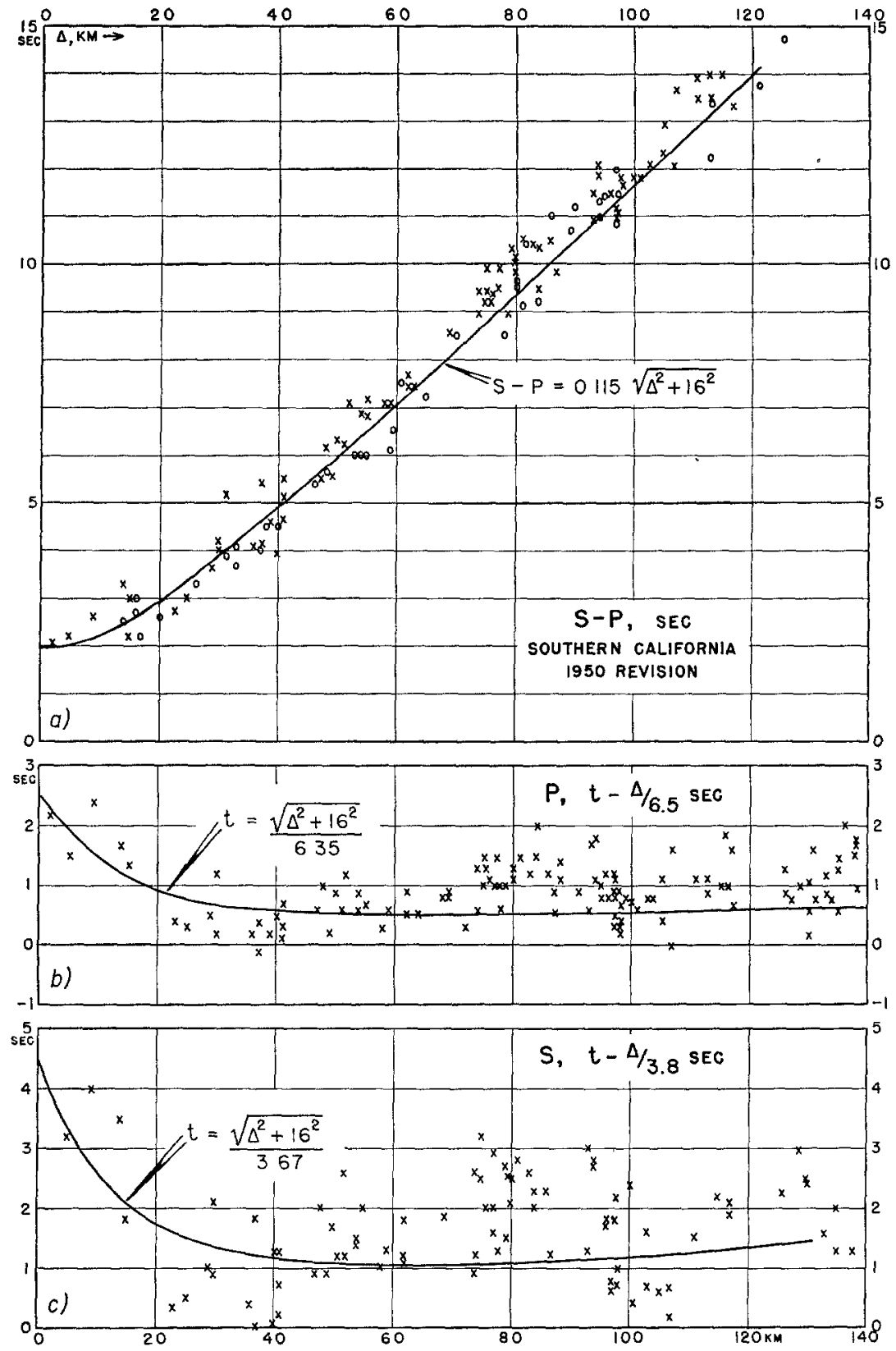

Fig. 1. Travel times of the direct $P$ and $S$ waves ( $p$ and $s$ ) in southern California earthquakes. $a) \mathrm{S}-\mathrm{P} . b) \mathrm{P}$ minus $\Delta / 6.5$. c) $\mathrm{S}$ minus $\Delta / 3.8(\Delta=$ epicentral distance in $\mathrm{km}$.). 
distance $\Delta$ from the epicenter can be calculated from equation (1) without use of origin times:

$$
d=C D \quad \text { where } \quad D^{2}=\Delta^{2}+h^{2} \quad \text { and } \quad C=(1 / v)-(1 / V)
$$

At short distances, $d$ is mainly affected by $h$, at greater diste nces mainly by $C$. From figure 1, $a$ it is found that on the average approximately $h=16 \mathrm{~km}$., $C=0.115$. The corresponding calculated curve for $d$ is entered in figure $1, a$.

By use of similar minimum assumptions, $V / v$ can be found as the ratio of time differences between corresponding $S$ and $P$ arrival times at pairs of stations in the same earthquake:

$$
V / v=\left(S_{2}-S_{1}\right) /\left(P_{2}-P_{1}\right)
$$

The average of 34 pairs of values gives $V / v=1.73 \pm 0.02$ (corresponding to Poisson's ratio of nearly 0.25 ). Combination of this value with $C=0.115$ results in $V=6.35 \mathrm{~km} / \mathrm{sec} ., v=3.67 \mathrm{~km} / \mathrm{sec}$. These values agree well with the velocities found from blasts (Gutenberg, 1950a) for the uppermost $16 \mathrm{~km}$. in southern California (see the beginning of this paper). They furnish the following relation of the travel time of $\mathrm{P}$ (or $P-O$, where $O=$ origin time) to $S-P$ at any given distance:

$$
P-O=1.37(S-P)
$$

Equation (3) permits the calculation of origin times for all those shocks in which at least one station is situated within an epicentral distance of less than about $140 \mathrm{~km}$. and has $\mathrm{P}$ and $\mathrm{S}$ clearly recorded; it was used for all shocks reported in the earlier paper for which this condition was fulfilled. The results are given in table 1; the first column refers to shocks with epicenters in the region of Haiwee (nos. 8 and 9); shocks numbered 13 to 16 with sources near the intersection of the San Andreas and the Garlock faults; no. 17 near Santa Barbara; and shocks 18 and 19 southeast of Mount Wilson. The second column corresponds to epicenters near the Inglewood fault; the third, to those in the regions of Elsinore and Riverside; the fourth, to earthquakes in the Little San Bernardino Mountains; and the last, to shocks west of Imperial Valley near the San Jacinto fault. Most of the origin times are between $3 / 4$ sec. and $1 / 2$ sec. later than those found in 1943.

The origin times of the standard Pasadena travel times for shallow teleseisms (Gutenberg and Richter, 1939, p. 96) were based on the earlier findings and especially on the travel times of the Long Beach earthquake of 1933 (no. 27 in table 1). It was assumed that the intercept time for Pn starting from a surface focus in southern California is 9 sec. This is found now to be only 
about 8 sec. or slightly less (see also the data from the Corona blast on August $6,1949$, fig. $3, c)$. Consequently, all travel times have to be reduced by 1 sec. or slightly more.

It has been suggested (Gutenberg, Wood, and Richter, 1933) to indicate the "direct" phases by the symbols $p$ and $s$, respectively. They correspond to the first segment of the phases $\mathrm{pP}, \mathrm{sP}$, etc., in deep-focus earthquakes. The travel

\section{TABLE 1}

Increase $o$ in Origin Time, Sotthern Caitfornia Shocks, 1933-1941, as a CoNSEQUENCE OF ReVised InTERPRETation OF PHASES

(Numbers $N$ of shocks as in Gutenberg, 1943, p. 508; $n=$ number of observations)

\begin{tabular}{|c|c|c|c|c|c|c|c|c|c|}
\hline $\mathrm{N}$ & $o$ & $N$ & $o$ & $\mathrm{~N}$ & $o$ & $\mathrm{~N}$ & 0 & $\mathrm{~N}$ & $o$ \\
\hline 8 & 0.8 & 20 & 1.2 & 28 & 0.9 & 36 & 1.3 & 46 & 1.2 \\
\hline 9 & 1.3 & 21 & 1.6 & 29 & 0.9 & 37 & 1.8 & 47 & 1.7 \\
\hline 13 & 0.5 & 22 & 0.9 & 30 & 0.8 & 38 & 1.4 & 48 & 0.9 \\
\hline 14 & 0.8 & 23 & 04 & 31 & 1.0 & 39 & 1.1 & & \\
\hline 15 & 0.5 & 25 & 0.5 & 32 & 1.0 & 40 & 1.6 & & \\
\hline 16 & 1.2 & 26 & 1.1 & 33 & 0.6 & 41 & 1.6 & & \\
\hline 17 & 0.7 & 27 & 1.1 & 34 & 0.8 & 42 & 1.4 & & \\
\hline 18 & 0.8 & & & 35 & 1.2 & 43 & 1.3 & & \\
\hline \multirow[t]{2}{*}{19} & 1.1 & & & & & 44 & 1.8 & & \\
\hline & & & & & & 45 & 1.4 & & \\
\hline \multicolumn{2}{|c|}{$\begin{array}{c}\mathrm{Avg} \ldots . .0 .9 \\
n=18\end{array}$} & \multicolumn{2}{|c|}{$\begin{array}{c}\text { Avg . . 1.0 } \\
n=19\end{array}$} & \multicolumn{2}{|c|}{$\begin{array}{c}\text { Avg } \ldots 0.9 \\
n=31\end{array}$} & \multicolumn{2}{|c|}{$\begin{array}{c}\text { Avg } \ldots 1.4 \\
n=10\end{array}$} & \multicolumn{2}{|c|}{$\begin{array}{c}\text { Avg } \ldots 1.4 \\
n=4\end{array}$} \\
\hline
\end{tabular}

times for $p$ and $s$ corresponding to constant velocities of 6.35 and $3.67 \mathrm{~km} / \mathrm{sec}$., respectively, and a focal depth of $16 \mathrm{~km}$., are given by

$$
t_{p}=D / 6.35 \quad t_{s}=D / 3.67 \quad \text { where } \quad D^{2}=\Delta^{2}+16^{2}
$$

and where the distance $\Delta$ is measured in kilometers. The corresponding curves are plotted together with the respective observations in figure $1, b$ and $c$; to permit the use of a larger scale, $\Delta / 6.5$ is subtracted from the times in the former, and $\Delta / 3.8$ from the times in the latter. Both curves fit the data well, considering that at the greater distances the beginning of the phases is read too late rather than too early. Most of the residuals are less than $1 / 2$ sec. for $p$ and less than 1 sec. for $s$. Several of the negative residuals at distances near $40 \mathrm{~km}$. in both figures belong to readings on Riverside records for the shocks numbered 32 to 35 , and several of the late readings near $\Delta=80 \mathrm{~km}$. to travel times of the wave from the same shocks to Pasadena and Mount Wilson. 
Moving the assumed epicenter for these shocks a few kilometers (well within the limits of the determination) in an easterly direction would reduce both groups of residuals. Some of the positive residuals for $s$ at distances between 80 and $100 \mathrm{~km}$. may result from incorrect interpretation of the records; the corresponding phase may not be $s$, as it was assumed, but the phase previously called "S33S" which follows $s$ at these distances after about 2 or 3 sec. (Gutenberg, 1944c, pp. 145 and 150) and is frequently much larger.

None of the three parts of figure 1 shows a break in the travel-time curves, which would result from the intersection of two branches. On the other hand,

TABLE 2

Travel Times of Direct P Waves (p) for Focal Depth $h$

(Column i, from equation 4; ii to iii, calculated on the following assumptions for the velocity $V$ in $\mathrm{km} / \mathrm{sec}$. as a function of the depth range $d$ in $\mathrm{km}$.:

$\begin{array}{rlll}\text { i: } d=h=16 ; V=6.35 \text { (no change with depth) } & \\ \text { ii: } d=5 ; V=5.6 ; & d=4 ; V=6.0 ; & d=7: V=6.5 ; & h=16 \mathrm{~km} . \\ \text { iii: } d=5 ; V=5.6 ; & d=5 ; V=6.0 ; & d=5 ; V=6.5 ; & h=15 \mathrm{~km} . \\ \text { iv: } d=3 ; V=5.6 ; & d=4 ; V=6.0 ; & d=9 ; V=6.5 ; & h=16 \mathrm{~km} .)\end{array}$

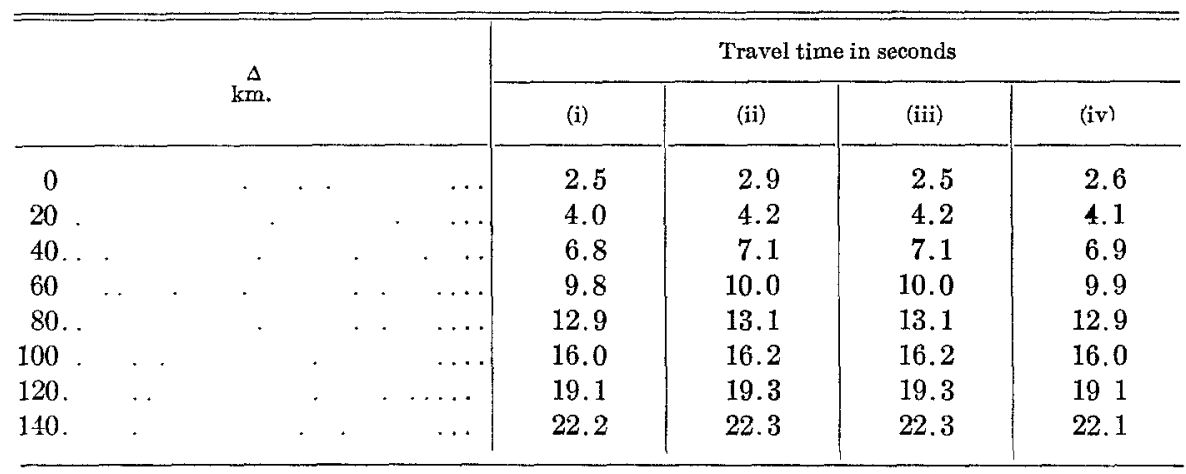

on the basis of the observed times, the differences between travel times calculated on different reasonable assumptions for the velocity as a function of depth are too small to permit deciding which of them is the best. In table 2, results of travel times calculated on the basis of different assumptions (guided by the results from blasts) are given. Velocities below the focal depth $h$ do not enter the calculation. Except for the shortest distances $\Delta$, for which there are few observations, the extreme differences between the four sets of calculated values are within $1 / 4 \mathrm{sec}$. Furthermore, the order of the layers does not affect the results. For example, on assumption ii it does not matter whether the layer assumed to be $5 \mathrm{~km}$. thick and with a velocity of $5.6 \mathrm{~km} / \mathrm{sec}$. is immediately above the focus or at the surface.

Additional information may be derived from the observed amplitudes, which have been reported in a previous paper (Gutenberg, 1945a). The loga- 
rithms of the average amplitudes of longitudinal waves in southern California which were tabulated for an earthquake of magnitude 5 (loc. cit., p. 290) are plotted in figure 2. The designations of the phases correspond to the revised interpretation, and some of them differ from those in the original table. For example, the phase indicated by diagonal crosses in figure 2 for distances less than $80 \mathrm{~km}$. was combined previously with that shown by the open circles, as

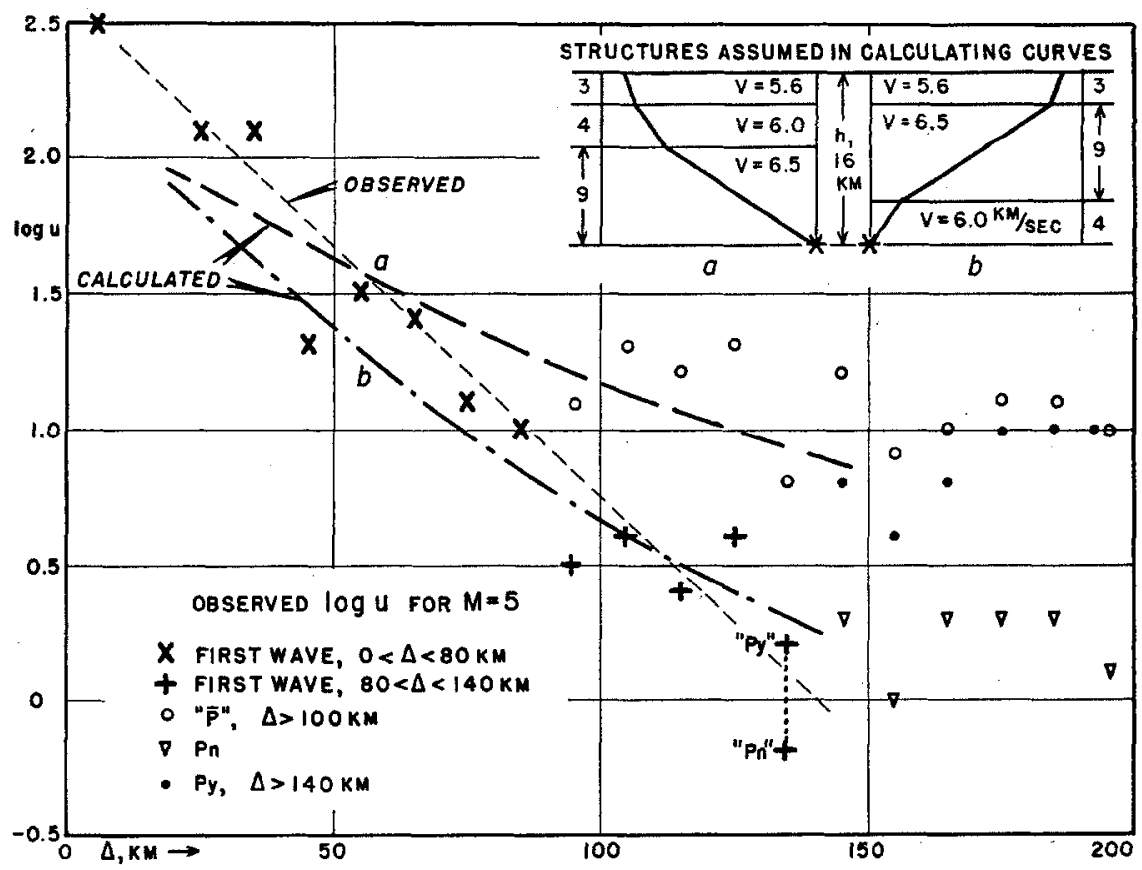

Fig. 2. Logarithms of amplitudes of various phases in southern California earthquakes.

pertaining to $\overline{\mathrm{P}}$, and the phase corresponding to the erect crosses with that represented by the dots, as pertaining to Py. The new interpretation combines all crosses of both types in figure 2 as giving the amplitudes of the direct $P$ waves $(p)$. The new interpretation results in much smoother curves for the change of the amplitudes of $p$ with distance, and the minima indicated in the earlier interpretation for $\overline{\mathrm{P}}$ at a distance of about $90 \mathrm{~km}$. and for Py at about $140 \mathrm{~km}$. have disappeared.

The remaining parts of the $\bar{P}$ and Py curves (distances beyond about 90 and $140 \mathrm{~km}$., respectively) correspond to waves in which the amplitudes change rather slowly with distance. This is to be expected, if both phases correspond to channel waves which are propagated along a low-velocity layer. On the other hand, the amplitudes of the direct $p$ waves (light barred line) decrease 
in exponential fashion with distance. The rate of this decrease as a function of distance depends mainly on the change in velocity with depth. This aids in selecting the most likely of several assumptions on the velocity-depth function which lead to approximately the same travel-time curves. For example, both distributions of velocities indicated as $a$ and $b$ in the curves inserted in the upper right-hand part of figure 2 give the same travel-time curve values as column iv in table 2 , but the calculated amplitudes of the corresponding $p$ waves (plotted in fig. 2) decrease much more slowly with distance on assumption $a$ than on assumption $b$. The observed amplitudes support the hypothesis that the wave velocity has a maximum between the source and the surface, since even the assumption of a constant velocity gives too small a decrease in amplitudes of the direct $P$ waves with distance.

Curves $a$ and $b$ in figure 2 were calculated from the following equation (Gutenberg, 1945b, pp. 57-58):

$$
u=C T-\frac{u}{A_{0}} \sqrt{F a \frac{-d \cos i_{h} / d \Delta}{\Delta \cos i_{0}}}
$$

where $u=$ horizontal component of the ground amplitude, $C=$ constant depending on the magnitude of the earthquake, $T=$ period, $F=$ energy ratio of refracted to incident energy passing through discontinuities, $a=$ factor to account for absorption, $\Delta=$ epicentral distance, $i_{0}$ and $i_{h}=$ angles of incidence at the surface and the source, respectively. The curves $a$ and $b$ in figure 2 were calculated for $\log C T=3.2$, which corresponds approximately to the value $C=6.3$ found from teleseisms (Gutenberg, 1945b, p. 61) on the assumption that $T=0.3$, that the magnification of the short-period torsion seismographs is 2,800 (note that the values plotted in figure 2 are trace amplitudes in $\mathrm{mm}$.), and considering that $\Delta$ was measured in $\mathrm{km}$. and that $(d \cos i) / d \Delta$ was calculated per $\mathrm{km}$. For the values of $i$ which are involved, the ratio $u / A$ of the horizontal displacement to the incident ground amplitude varies between about 1.5 and 1.7 for $\Delta$ between about 20 and $140 \mathrm{~km}$., and $F$ is between about 0.9 and 0.6 under the circumstances involved (Gutenberg, 1944b, p. 99 and p. 95, respectively). The absorption factor $a$ is assumed to be 1.0 ; for an epicentral distance of $1,000 \mathrm{~km}$. it is about 0.9 . Cos $i_{0}$ varies between about 0.7 and 0.4 in the range of $\Delta$ involved. All these quantities differ relatively little on the various assumptions made in the present paper. The main difference results from $d(\cos i) / d \Delta$. At a distance of $90 \mathrm{~km}$. it is about 0.0002 per $\mathrm{km}$., if on assumption iv in table 2 the layer with $V=5.6 \mathrm{~km} / \mathrm{sec}$. is at the bottom of the column; it is about 0.0003 per $\mathrm{km}$. if the layer with $V=6.0$ is at the bottom of the column (at the source), but about 0.0015 if the velocity increases with depth in the three layers from $5.6 \mathrm{~km} / \mathrm{sec}$. at the surface to 


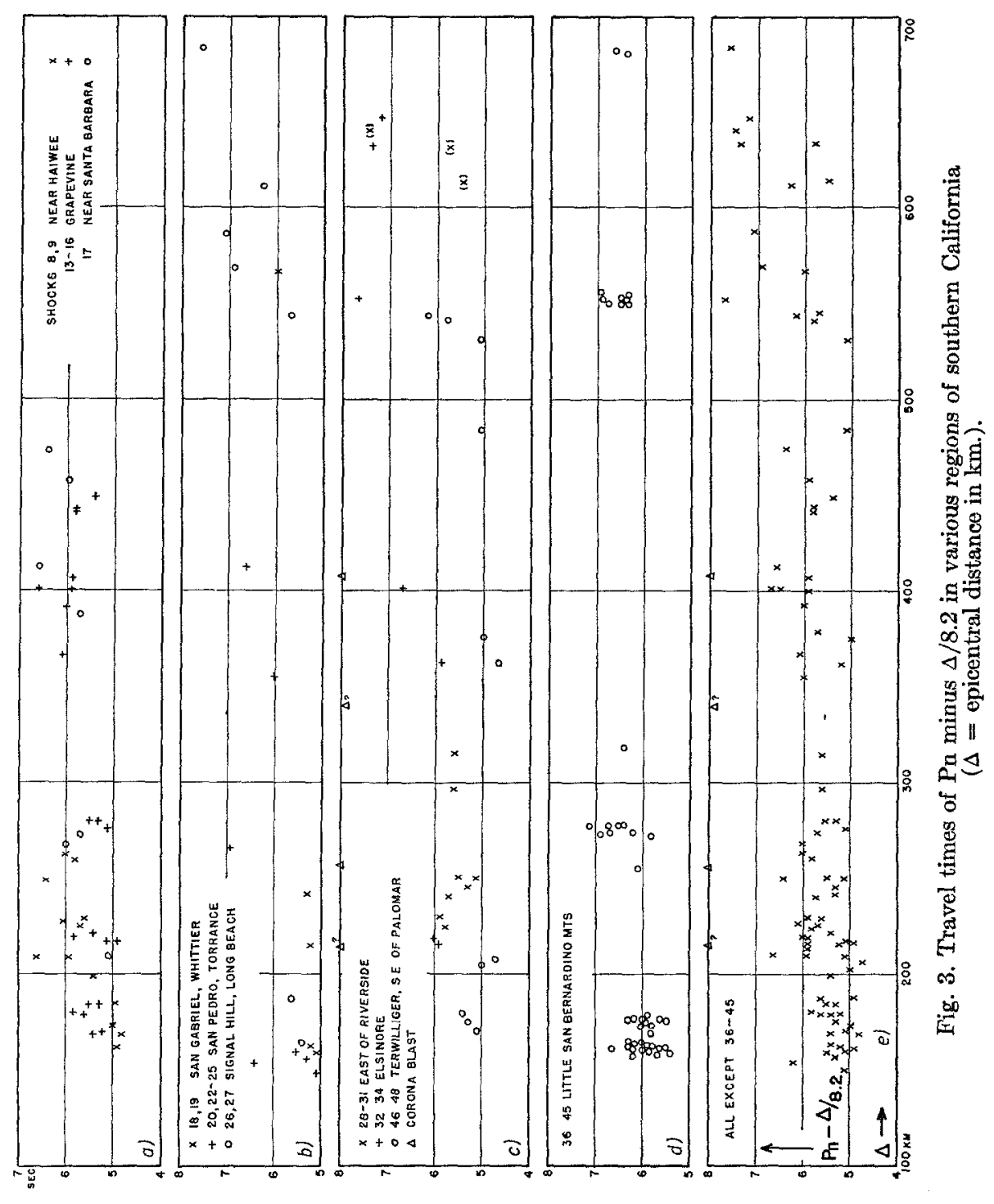


6.5 at the source. The effect can be visualized from the insert in figure 2 , considering that on assumption $b$ the angle of incidence $i_{h}$ of the ray at the source is appreciably smaller than that on assumption $a$. Thus more energy arrives at the surface between the epicenter and the distance $\Delta$ (which is the same on both assumptions) in case $a$ than in case $b$.

For constant velocity between the source and the surface and with $a=1$, equation (5) may be written

$$
u=C T(u / A) / D
$$

where $D$ is given by equation (4). Calculated values are close to curve $a$.

Travel times of Pn were recalculated using the new origin times. They are plotted in figure 3 as a function of distance (after deduction of $\Delta / 8.2$ to permit use of a large scale) for several selected epicentral regions. Shocks numbered 1 to 7 with epicenters in Owens Valley are omitted since in these shocks the data for $\mathrm{S}-\mathrm{P}$ at distances less than about $100 \mathrm{~km}$. are too scanty for the calculation of origin times. The average correction in five shocks with one observation of $\mathrm{S}-\mathrm{P}$ in each is 0.6 sec., which would increase the calculated effect of the "root of the Sierra" on Pn of these shocks by about $1 / 2$ sec.

In figure $3, e$ all revised travel times for $\mathrm{Pn}$ are plotted except those in shocks numbered 36 to 45 (epicenter in the Little San Bernardino Mountains), in which Pn shows a delay as noted in the earlier paper. Figure 3 indicates that the apparent velocity of Pn is slightly less than $8.2 \mathrm{~km} / \mathrm{sec}$. In drawing a representative travel-time curve it has to be considered that at the shorter distances (less than about $180 \mathrm{~km}$. in figure 3, $d$; less than $160 \mathrm{~km}$. in the others) the first arrival may not be connected with Pn; at the greater distances the earlier points should be given more weight than the late points since it is likely that many of the later readings do not correspond to the first motion, which may have been too small to be clearly recorded. On the basis of figure $3, e$ it was tentatively assumed that in shocks originating in the coastal areas of southern California the travel time of $\mathrm{Pn}$ is given by

$$
t_{n}=5.1+\Delta / 8.1=5.1+0.1235 \Delta
$$

For epicenters in the region of the Little San Bernardino Mountains the constant term would be about 6 sec., and in earthquakes originating in northern Owens Valley about 8 to 9 sec.

Figure 3, $c$ and $e$, includes data for Pn observed in the Corona blast on August 6, 1949 (Gutenberg, 1950a). Seismograms recorded at Boulder City and Pierce Ferry were kindly supplied by Mr. Frank H. Werner, Chief of the Lake Mead Seismological Survey (United States Coast and Geodetic Survey). Pn was clearly recorded at Haiwee $(\Delta=257 \mathrm{~km}$.) and Pierce Ferry $(\Delta=407$ $\mathrm{km}$.). The beginnings at Santa Barbara $(214 \mathrm{~km}$.) and Boulder City $(340 \mathrm{~km}$.) 


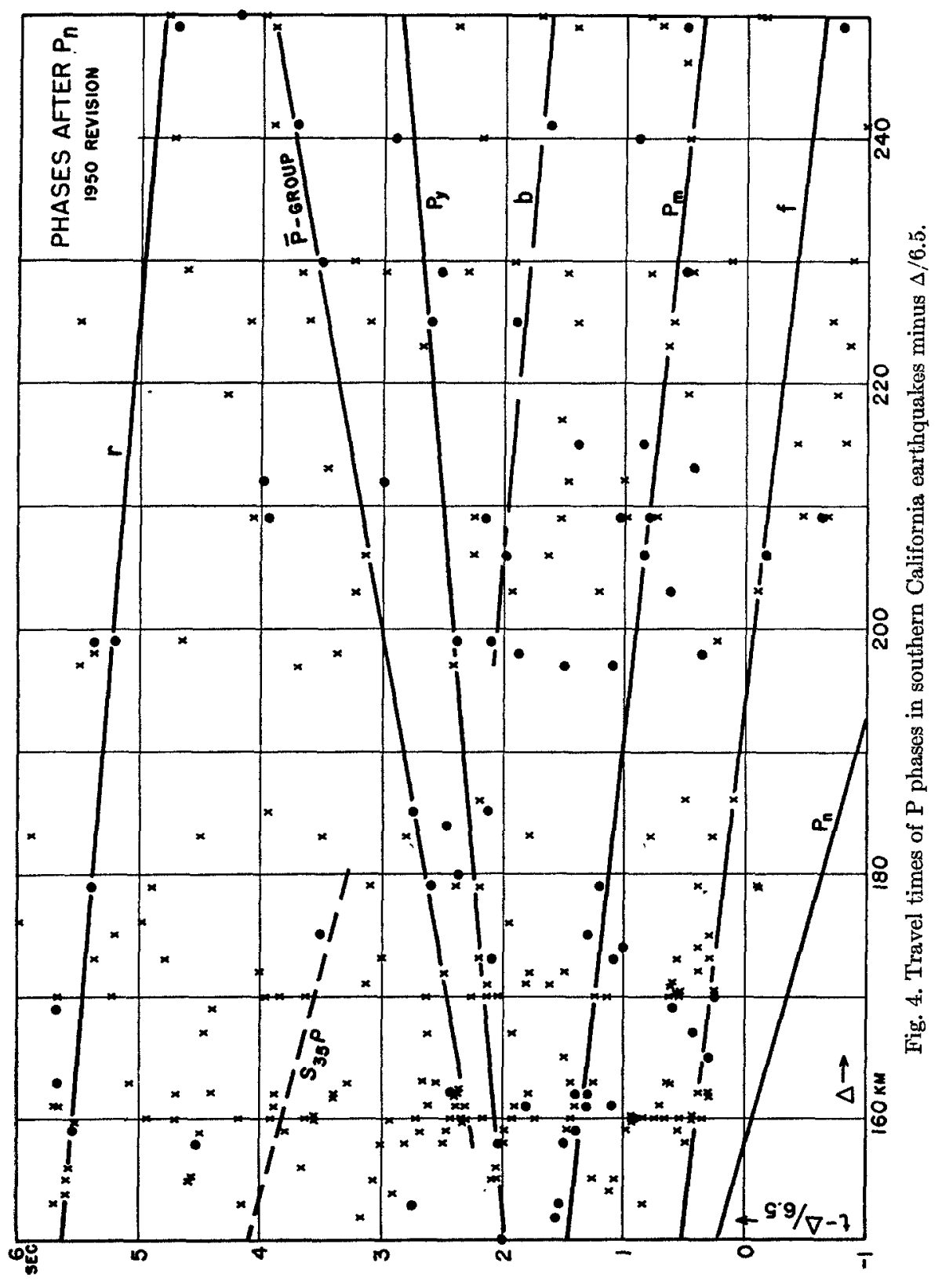


are less distinct. Figure 3 shows that in this blast the travel time of $\mathrm{Pn}$ is approximately given by

$$
t_{n}=8.0+\Delta / 8.2
$$

The distance at which the Pn travel-time curve and that of the direct wave from southern California earthquakes intersect, that is, the distance beyond which Pn arrives first, depends on the region. For most coastal areas in southern California the revised curves give about $150 \mathrm{~km}$. In the mountain areas this distance should be larger; figure $3, d$ indicates about $180 \mathrm{~km}$. for the Little San Bernardino Mountains. The corresponding travel-time curves for shocks originating in northern Owens Valley seem to intersect at epicentral distances greater than $200 \mathrm{~km}$., if the thickness of the upper layers there is the same as in the other areas in southern California.

The difference $d$ between the travel times of Pn from a source at the surface and those from an earthquake at the depth $h$ in the same region can be used to determine $h$ without making any assumption concerning the wave velocity between the depth of the focus and the Mohorovičic discontinuity. If $V_{0}$ is the mean velocity between the earthquake focus and the surface of the earth (supposed to be constant), and $V_{n}$ the velocity below the Mohorovicic discontinuity, then

$$
h=d V_{0} V_{n} \sqrt{1 /\left(V_{n}^{2}-V_{0}^{2}\right)}
$$

which gives $h=$ about $10 d$, if $V_{0}=6.35 \mathrm{~km} / \mathrm{sec}$. and $V_{n}=8.1 \mathrm{~km} / \mathrm{sec}$.

The epicenters nearest to the source of the Corona blast are shocks numbered 32 to 34 (marked by erect crosses in fig. $3, c$ ). The corresponding travel times of Pn are about 2 sec. shorter than those in the blast (marked by triangles in fig. $3, c$ ). Thus, equation (9) indicates a depth $h$ of about $20 \mathrm{~km}$., or slightly less, if the observation at a distance of $401 \mathrm{~km}$. (Fresno) is included.

Contrasting with this method of finding $h$, the depth of the Mohorovičic discontinuity cannot be determined without assuming values for the wave velocities in the intervening layers. Consequently, no correct depth can be found for it at the present stage of investigation. Fortunately, different assumptions within reasonable limits do not result in large differences in the calculated depth. The thickness $d_{4}$ (corresponding wave velocity $V_{4}$ ) of the layer above the Mohorovičic discontinuity may be found from

$$
\begin{aligned}
& d_{4}= \\
& \frac{V_{n} \tau_{n}-d_{\mathrm{I}} \sqrt{\left(V_{n} / V_{1}\right)^{2}}-\overline{1}-d_{2} \sqrt{\left(\bar{V}_{n} / \bar{V}_{2}\right)^{2}-1}-\left(2 d_{3}-h+d_{1}+d_{2}\right) \sqrt{\left(\bar{V}_{n} / \bar{V}_{3}\right)^{2}-1}}{2 \sqrt{\left(\bar{V}_{n} / \bar{V}_{4}\right)^{2}-1}}
\end{aligned}
$$

where it is assumed that the focus (depth $h$ ) is in the third layer below the surface (thickness $d_{3}$, velocity $V_{3}$ ), that the indices 1 and 2 refer to the two 


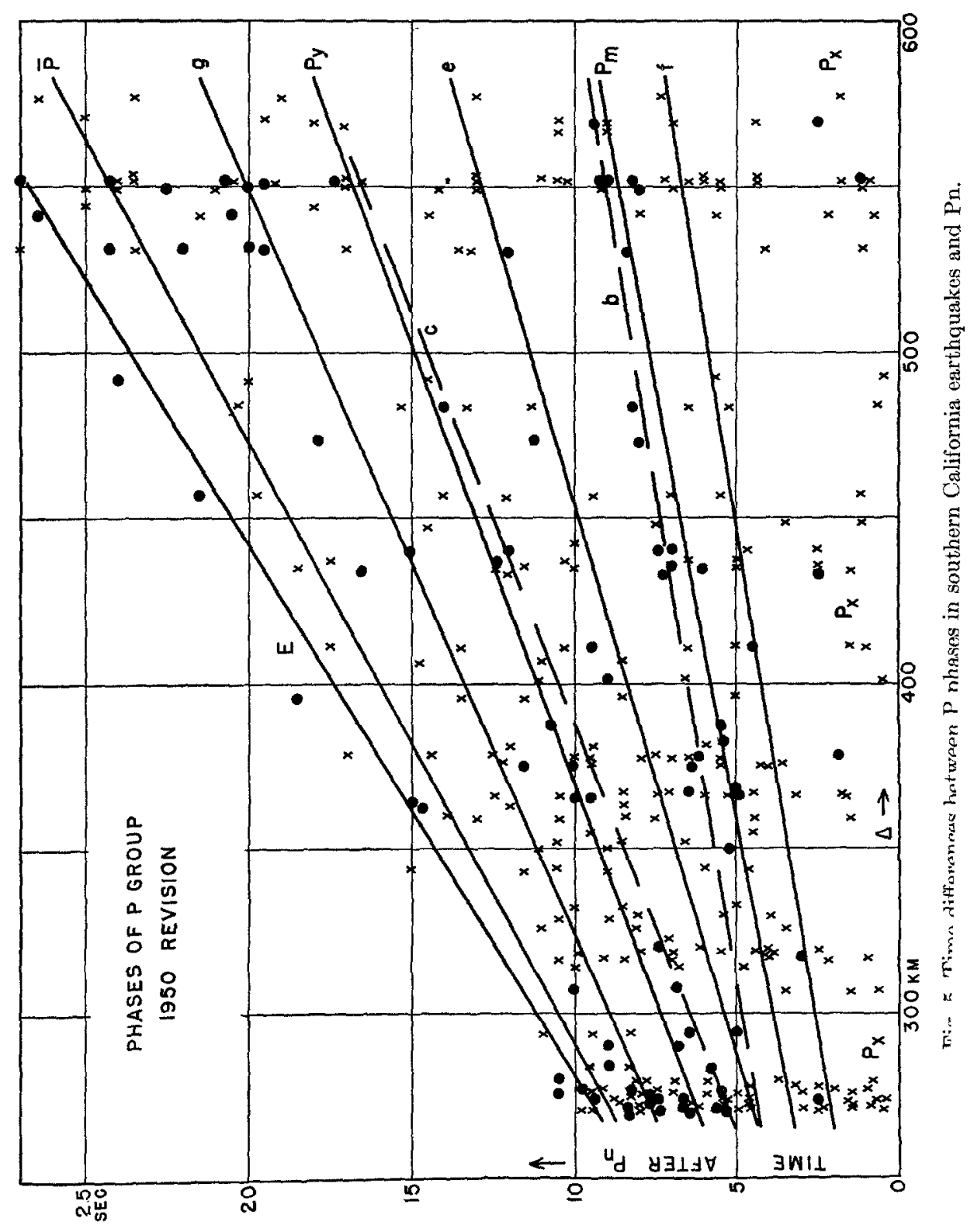


upper layers (found from blasts), and that the travel time of Pn is given by $\tau_{n}+\Delta / V_{n}$. If the source is at the surface, the coefficients in front of the square roots in the numerator are $2 d_{1}, 2 d_{2}$, and $2 d_{3}$, respectively. Solutions based on assumptions for $d_{2}, d_{3}$, and $V_{3}$ which seem most likely at present give tentatively about $35 \mathrm{~km}$. for the depth of the Mohorovičic discontinuity in the southern California coastal areas, about $40 \mathrm{~km}$. from earthquakes in the mountain areas to the east and from the Corona blast, and roughly $60 \mathrm{~km}$. in the Sierra region.

Other $\mathrm{P}$ phases to be discussed now include $\mathrm{Py}, \mathrm{Pm}$, and $\overline{\mathrm{P}}$ at epicentral distances of over about $100 \mathrm{~km}$. Travel times of clear phases within the $\mathrm{P}$ group of the earthquakes used previously (Gutenberg, 1944a) have been redetermined independently of previous measurements. Origin times of the shocks as revised in table 1 were used. On some clear seismograms for which origin times or time corrections were in doubt, time intervals between welldefined phases and the beginning of the seismogram have been determined. All readings have been plotted in various ways (e.g., travel time minus $\Delta / 6.5$ (fig. 4) or travel-time differences after Pn (fig. 5) to get the advantage of relatively large time scales. Before the curves of figures 4 and 5 (and similar curves in other unpublished figures) were drawn, the phases were studied repeatedly on the records to aid the final drawing of travel-time curves by combining points corresponding to waves of similar appearance.

Table 3 contains the elements of the most prominent travel-time curves (all supposed to be straight lines). Frequently, Pn has the longest period of the $\mathrm{P}$ group, usually more than 1 sec. This may be a consequence of the fact that the layer below the Mohorovičic discontinuity extends at least to a depth of about $80 \mathrm{~km}$. and is much thicker than any of those above. Px is a much shorter wave which often starts with an impulse before the first Pn wave is completed; it has periods of a fraction of a second. It has been suggested repeatedly that $\mathrm{Px}$ should be explained in terms of wave mechanics rather than as a wave refracted through an additional layer. If the latter were the correct interpretation, such a layer would be very thin and the velocity of longitudinal waves in this layer would be close to $8 \mathrm{~km} / \mathrm{sec}$. The time interval $\mathrm{Px}-\mathrm{Pn}$ increases from about 1 sec. at $\Delta=200 \mathrm{~km}$. to about 2 sec. at $\Delta=600 \mathrm{~km}$. (fig. 5).

The phase "d" (table 3) corresponds to relatively small impulses which have been found at distances between about $550 \mathrm{~km}$. (points between $\mathrm{f}$ and $\mathrm{Px}$ at the right-hand end of fig. 5) and about $800 \mathrm{~km}$. There is some doubt whether the points on which $\vec{V}$ and $\tau$ for $d$ in table 3 are based belong to a continuous curve. The interpretation of the phase " $\mathrm{d}$ "-if real-is difficult. The relatively large intercept time practically excludes the assumption that $d$ corresponds to a refracted wave.

The travel-time curve of $\mathrm{f}$ (table 3 ; figs. 4 and 5) is approximately tangent 
to the curve of the reflected wave marked previously P33P, and the calculated depth of an assumed discontinuity causing the refraction of $f$ would be about $29 \mathrm{~km}$. An increase in velocity can be.expected somewhere at a depth between about 25 and $30 \mathrm{~km}$., for various reasons; for example, from the boundary between sialic and simatic rock, or from the transition from alpha- to betaquartz in granitic material. Velocities of slightly more than $7 \mathrm{~km} / \mathrm{sec}$. at such depths have been found in many regions.

The next two curves, marked Pm and $\mathrm{b}$ in figures 4 and 5, are less than 1 sec. apart and may belong to phases with paths differing only for a small segment. $\mathrm{Pm}$ is usually more prominent than either $\mathrm{f}$ or $\mathrm{d}$. If $\mathrm{f}$ is not a refracted wave, then Pm may correspond to a longitudinal wave refracted at a depth of about

TABLE 3

Apparent Veloctry $\bar{V}$ in km/sec. and Intercept Time $\tau$ of Travel-Time Curves Plotted in Figdres 4 and 5

( $\tau$ is greater for $\mathrm{Pn}$ in shocks originating in mountain areas)

\begin{tabular}{|c|c|c|c|c|c|c|c|c|c|c|c|c|}
\hline Phase & $P_{n}$ & $P x$ & d & $f$ & $\mathrm{~b}$ & $\mathrm{Pm}$ & e & $\mathrm{c}$ & $\mathrm{Py}$ & $g$ & $\overline{\mathrm{P}}$ & $\mathbf{E}$ \\
\hline $\bar{V}$ & 8.10 & $7.9 \pm$ & $7.66 ?$ & 7.15 & 7.09 & 7.01 & 6.54 & 6.22 & 6.21 & 5.95 & 5.56 & 5.3 \\
\hline $10,000 / \bar{V}$ & 1,235 & 1,266 & $1,305 ?$ & 1,399 & 1,410 & 1,427 & 1,529 & 1,608 & 1,610 & 1,681 & 1,799 & 1,887 \\
\hline$\tau$. & 5.1 & 5.4 & $6.7 ?$ & 2.8 & 4.7 & 3,5 & 18 & 0.2 & 1.2 & 0.7 & -1.2 & -3 \\
\hline
\end{tabular}

$34 \mathrm{~km}$. However, this explanation is somewhat doubtful since the layer in which $\mathrm{Pm}$ is propagated could be only a few kilometers thick. On the other hand, Pm and $b$ may be waves which have paths similar to that of $f$, but which have traversed one or two segments as transverse waves. There are other explanations.

It is difficult to interpret any of the phases following $\mathrm{Pm}$ in table 3 (later than $\mathrm{b}$ in figs. 4 and 5) as due to refraction or reflection at a discontinuity. The apparent velocities of these phases are $6.5 \mathrm{~km} / \mathrm{sec}$. or less. Since a velocity of about $6.8 \mathrm{~km} / \mathrm{sec}$. has been established from blast records in southern California for a depth of about $12 \mathrm{~km}$., waves passing through a deeper layer with a velocity of $63 / 4 \mathrm{~km} / \mathrm{sec}$. or less would not return to the surface before they have reached a still deeper layer with greater velocity.

In many seismograms Py (or occasionally already $\mathrm{Pm}$ ) is the beginning of a more or less continuous group of short-period phases (period usually a fraction of a second) in which $\mathrm{g}, \overline{\mathbf{P}}$, and $\mathrm{E}$ (figs. 4 and 5) mark impulses with greater amplitudes and frequently slightly shorter periods. At distances up to about $160 \mathrm{~km}$., Py and $\overline{\mathrm{P}}$ are rarely clear phases. While the amplitudes of the refracted waves decrease noticeably with distance, $\mathrm{Py}$ and $\overline{\mathrm{P}}$ seem to reach their absolute maxima at distances of about $190 \mathrm{~km}$. (fig. 2). The ratio of their amplitudes to those in the preceding part of the seismograms increases 
appreciably with distance $\Delta$, if $\Delta$ approaches $200 \mathrm{~km}$. Beyond $\Delta=200 \mathrm{~km}$., the duration of the $\mathrm{Py}-\overline{\mathrm{P}}$ group increases with distance. The maximum amplitudes of $\overline{\mathrm{P}}$ decrease more slowly than those of other $\mathrm{P}$ phases, so that $\overline{\mathrm{P}}$ becomes the outstanding phase of the part of the seismogram which precedes $\mathrm{S}$. $\mathrm{E}$ is also frequently a strong phase. At distances between about 300 and 400

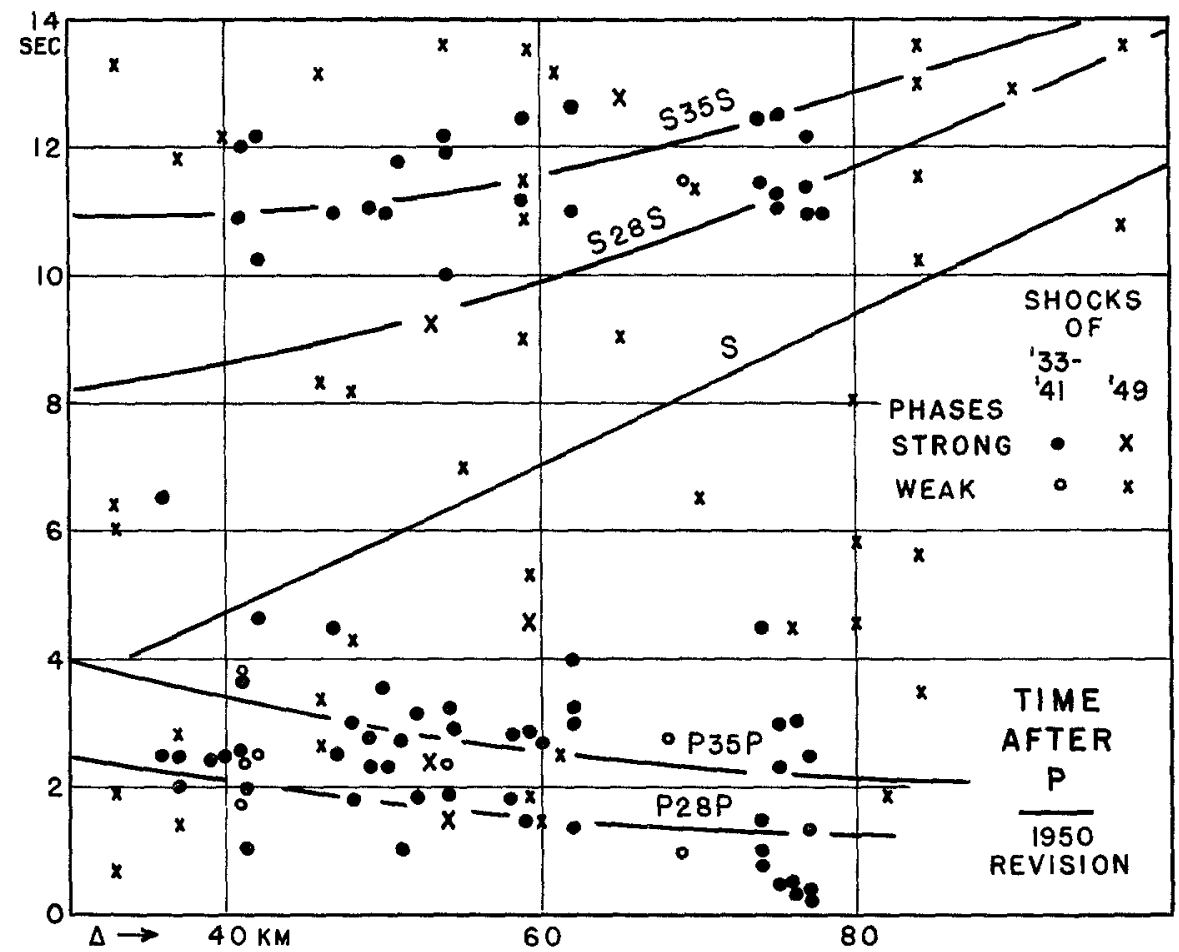

Fig. 6. Observed time differences between reflected waves in southern California earthquakes and the first $P$ waves.

$\mathrm{km}$. the beginning of all phases between Py and E becomes less clear. Additional impulses appear between $g$ and $\bar{P}$. At distances between about 450 and $600 \mathrm{~km}$. the group extends over a time interval of $1 / 2 \mathrm{~min}$. to $1 \mathrm{~min}$. with no well-determined travel-time curves of the various impulses. At still greater distances it becomes impossible to draw definite travel-time curves for the later $\mathrm{P}$ waves. The corresponding part of the seismogram is then characterized by more or less continuous waves decreasing rather rapidly with distance $\Delta$, while the periods seem to increase with $\Delta$; periods of 1 sec. or more are frequently dominant.

Valuable information concerning discontinuities can frequently be derived from the observation of reflected waves. The phases P33P, P37P, etc., studied 
previously (Gutenberg, 1944c, pp. 144-150) are good examples. The parts of the seismograms preceding these phases were reëxamined in an attempt to find earlier reflected waves. None are outstanding in the records available. However, this may be due to the fact that reflections from relatively shallow discontinuities would follow $\mathrm{P}$ rather elosely.

Figure 6 shows observed times after $P$ of reflected waves. Time differences were read directly from the older seismograms, and data for the smaller shocks of 1949 studied by C. F. Richter (1950) were added. Travel times $t$ and corresponding distances $\Delta$ can be calculated from

$$
\Delta=\sum_{1}^{n} d_{n} \tan i_{n} \quad t=\sum_{1}^{n} d_{n} / V_{n} \cos i_{n}
$$

where $d$ is the thickness of the 1st, $2 \mathrm{~d}, \ldots$ nth layer through which the wave travels, and $i$ the angle of incidence in each layer, determined by Snell's law from the velocities $V$ in each layer. For the layer in which the wave starts, $d$ has to be taken from the depth of focus down to the next discontinuity. Equation (11) permits rapid calculation of travel times of reflected waves on different reasonable assumptions for $d$ and $V$. The results show that $d$ and $V$ cannot be found with high accuracy from a given travel-time curve of a reflected wave. Especially, it seems unlikely that the effect of a layer with relatively low velocity at a depth near $20 \mathrm{~km}$. can be found from travel-time curves of waves reflected at a deeper discontinuity unless the thickness of such a low-velocity layer and the decrease in velocity are appreciably greater than is expected.

For the calculation of the travel-time curves shown in figure 6 it has been assumed that the following values apply: depth of focus, $16 \mathrm{~km}$.; $d_{1}=28 \mathrm{~km}$; longitudinal velocity, $V_{1}=6.35 \mathrm{~km} / \mathrm{sec}$; transverse velocity, $v_{1}=3.67$ $\mathrm{km} / \mathrm{sec}$; $d_{2}=7 \mathrm{~km}$.; $V_{2}=7.15 \mathrm{~km} / \mathrm{sec}$.; $v_{2}=4.14 \mathrm{~km} / \mathrm{sec}$. The calculated travel-time curves in figure 6 agree well with the observed travel times. A still better agreement can be achieved on slightly different assumptions. The observed travel times for waves assumed to be reflected at a depth of $35 \mathrm{~km}$. scatter more than those for the reflection at a depth of $28 \mathrm{~km}$., especially for "S35S." This is to be expected since the depth of the reflecting layer is known to be greater under the mountain areas of southern California than under the coastal regions.

In addition to the curves plotted in figure 6, travel-time curves have been calculated for S28P (which follows P35P after about 0.3 sec. at $\Delta=40 \mathrm{~km}$. and after about 1 sec. at $\Delta=80 \mathrm{~km}$.), for $\mathrm{S} 35 \mathrm{P}$ (about $1 \frac{1}{2}$ sec. after $\mathrm{S} 28 \mathrm{P}$ ), P28S, and P35S. A part of the calculated travel-time curve of $\$ 35 \mathrm{P}$ is indicated in figure 4 . It is not marked by outstanding observations. The calculated curve for P35S follows the observed curve " $r$ " near the top of figure 4 by about 1 sec. 
The $\mathbf{S}$ phase have been studied in the same way as the $\mathbf{P}$ phases. Like the $\mathrm{P}$ phases, the $\mathrm{S}$ phases may be divided into two groups. The first contains relatively clear waves of short duration and relatively small amplitudes, and the second is characterized by more or less continuous motion with waves of greater amplitudes and frequently no clear beginning. Usually, in this second part of the $\mathrm{S}$ group each new increase in amplitude begins before the preceding phase has died down. Except for the larger earthquakes (magnitude approaching or surpassing 6), the prevailing periods are mostly of the order of 1 sec. In the larger earthquakes the later phases are rarely distinct.

$\mathrm{Sn}$ is often a rather clear phase. (For seismograms see Gutenberg, 1944a, p. 13 and $1944 \mathrm{c}$, p. 152.) Travel times (after deducting $0.225 \Delta$ ) are plotted in figure 7, $a$ for shocks numbered previously (Gutenberg, 1944a), 8 to 35, 47, and 48 , omitting the data from earthquakes with epicenters in Owens Valley (nos. 1 to 7 ) and in the Little San Bernardino Mountains (nos. 36 to 46) where, as in Pn, greater intercept times of the travel-time curves are found. The observations can be represented by

$$
t=8.4+0.220 \Delta
$$

which corresponds to an actual velocity of about $4.5 \mathrm{~km} / \mathrm{sec}$. The previous result (Gutenberg, $1944 a, \mathrm{p} .31$ ) was $t=81 / 2+0.225 \Delta$ (or about $t=71 / 2+$ $0.225 \Delta$, considering the revised origin times). The difference is within the limits of error (see fig. $7, a$ ). The ratio of the velocities of $\mathrm{Pn}$ and $\mathrm{Sn}$ is about 1.78. This corresponds to a value of Poisson's ratio of 0.27 . The reciprocal of the ratio of the intercept times is about 1.64. Thus, the agreement between the two corresponding phases is good.

Sn is frequently followed by a phase which has been called $\mathrm{Sx}$, since it seems to correspond to $\mathrm{Px}$. The time interval $\mathrm{Sx}-\mathrm{Sn}$ (fig. 7,b) increases from about $1 / 2$ sec. at $\Delta=250 \mathrm{~km}$. to about $1 \frac{1}{2}$ sec. at $\Delta=700 \mathrm{~km}$. Many observations of smaller $\mathrm{Sx}$ waves (and also most of the relatively small observations of $\mathrm{Sa}$ ) are not plotted in figure $7, b . \mathrm{Sx}$ is followed by $\mathrm{Sa}$, which corresponds to the phase called $\mathrm{Sm}$ in the earlier papers on southern California earthquakes. The travel times of Sa are approximately given by

$$
t=5.5+0.242 \Delta=5.5+\Delta / 4.14
$$

This agrees within the limit of errors (considering the revised origin time) with $6.9+0.244 \Delta$ found previously for $\mathrm{Sm}$. The line given by (13) is approximately tangent to the curve for $\mathbf{S 2 8 \mathrm { S }}$ (fig. 6) and corresponds probably to a transverse wave refracted at a depth of roughly $28 \mathrm{~km}$. The velocity ratio for $\mathrm{Sa}$ and the longitudinal wave $\mathrm{f}$ (table 3 ) is about 1.73 , corresponding to a value of Poisson's ratio of 0.25 . The two intercept times have also about the ratio to be expected, if $\mathrm{f}$ and $\mathrm{Sa}$ are refracted at the same depth. 

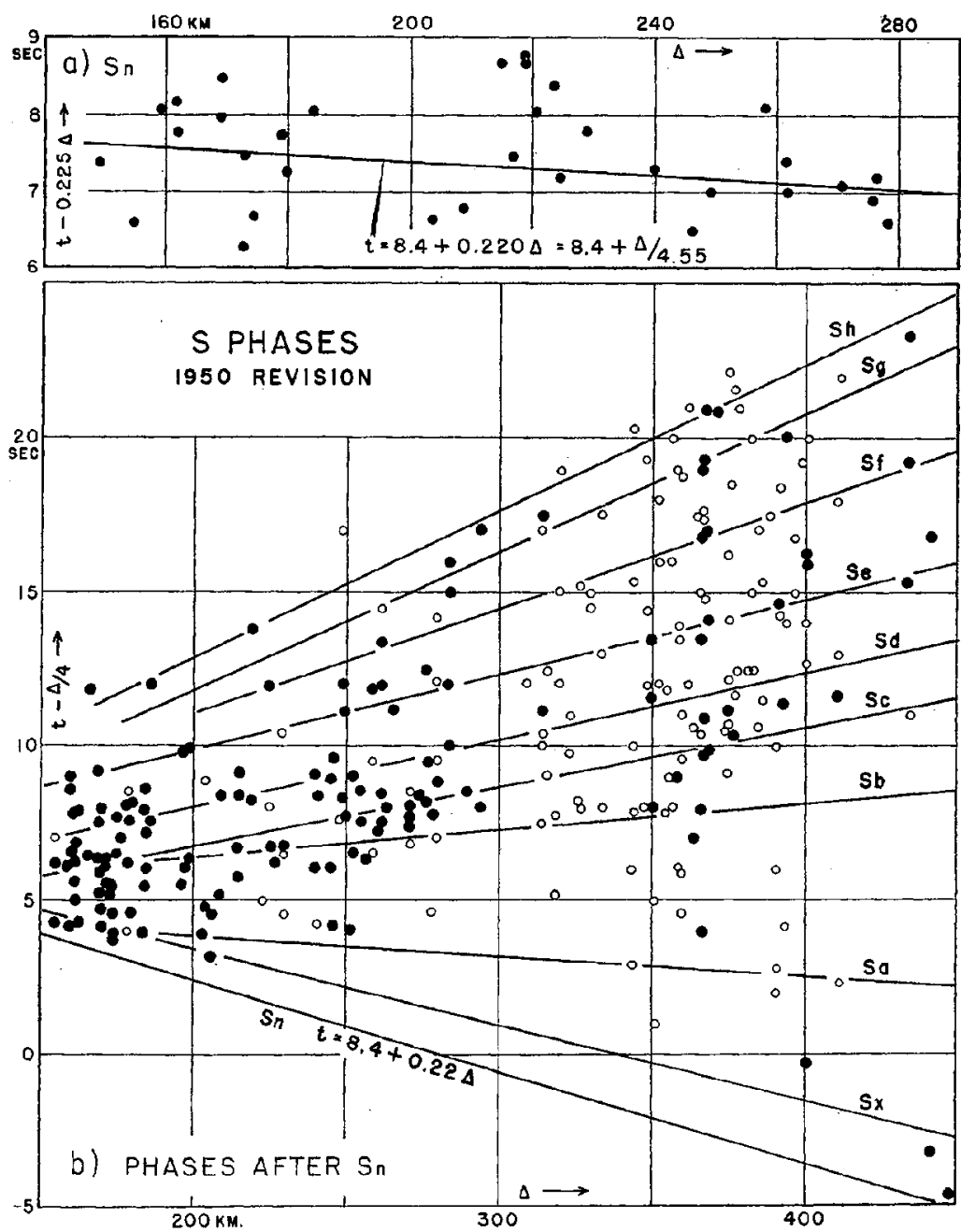

Fig. 7. a. Travel times of $\mathrm{Sn}$ in southern California earthquakes minus $0.225 \Delta$ $b$. Travel times of $\mathrm{S}$ phases in southern California earthquakes minus $\Delta / 4$. (Only observations corresponding to phases with large amplitudes are plotted; $\Delta=$ epicentral distance in $\mathrm{km}$.)

Apparent velocities $V$ and intercept times $\tau$ for the travel-time curves of the later $\mathbf{S}$ phases plotted in figure $7, b$ are given in table 4 . In general their appearance is similar to that of the P'phases starting with e in table 3 . The intercept times (which are about $1 / 2$ sec. to 2 sec. for the $P$ waves) are about $21 / 2$ to $41 / 2$ sec. for the $\mathrm{S}$ waves. The accuracy of these values is not great 
(see fig. 7, b). The curves were plotted after repeated study of the seismograms; they connect phases of similar appearance. The apparent velocities decrease about proportionally to those of the $\mathrm{P}$ phases (ratio $\mathrm{P} / \mathrm{S}$ about 1.7). The first phases of table 4 are dominant at the shorter distances, the later phases at the greater distances. At distances near $\Delta=200 \mathrm{~km}$., Sb or $\mathrm{Sc}$ are usually the largest phases of the whole seismogram, and there are some-

TABLE 4

Apparent Velocity $\bar{V}$ in km/sec. and Intercept Times $\tau$ of Travel-Time Curves Marked in Figdre 7, $b$

\begin{tabular}{|c|c|c|c|c|c|c|c|}
\hline Phase & $\mathrm{Sb}$ & $\mathrm{Sc}$ & Sd & $\mathrm{Se}$ & $\mathrm{Sf}$ & $\mathrm{Sg}$ & $\mathrm{Sh}$ \\
\hline $\bar{V}$. & 3.85 & 3.71 & 3.68 & 3.64 & 3.52 & 3.39 & 3.37 \\
\hline$\tau \ldots \ldots$ & 4.3 & 2.8 & 3.6 & 4.9 & 4.3 & 2.8 & 4.6 \\
\hline
\end{tabular}

TABLE 5

Mean logartihms of Trace Amplitudes (in mm.) of S Waves in Southern Calfornia Earthquakes to Be Expected for a Shock of Magnitude 5 on the Horizontal Component of a Standard Wood-Anderson Torsion Seismograph at a Given Distance $\Delta$ (IN KM.)

(The symbol s is used for the "direct S")

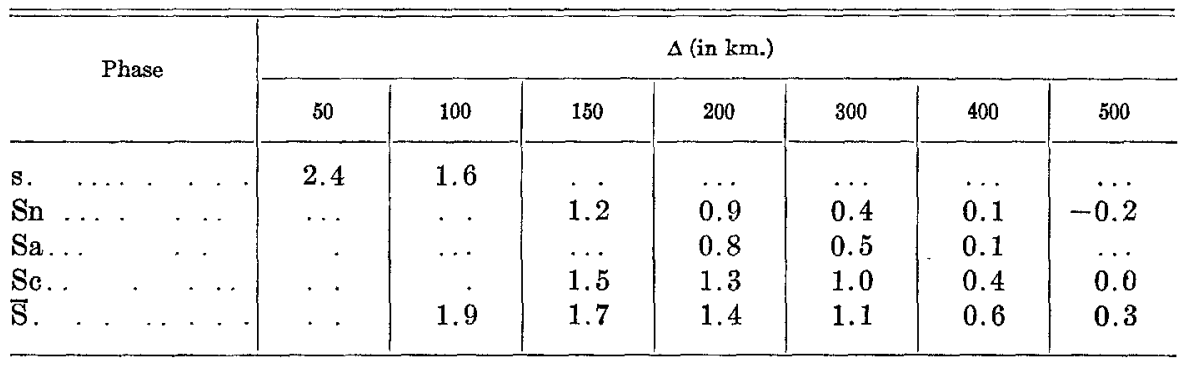

times no clear or large later phases. At $\Delta=300 \mathrm{~km}$., Se is usually the dominant phase and leads the more or less continuous motion in the second part of the $\mathrm{S}$ group. This phase was previously indicated by the symbol SySy. At distances near $500 \mathrm{~km}$., Sf (previously SySySy) becomes the dominant phase (for characteristic seismograms see Gutenberg, 1944c, p. 150).

At distances greater than about $100 \mathrm{~km}$. the phase previously called $\overline{\mathrm{S}}$ corresponds roughly to the beginning of the maximum in the $\mathrm{S}$ group. It does not appear to belong to a definite phase, but seems to move to later and later phases as the distance increases. A similar explanation may apply to $\overline{\mathrm{P}}$ at distances greater than about $100 \mathrm{~km}$., but the evidence for such an interpretation of $\overline{\mathrm{P}}$ is less clear than for $\overline{\mathrm{S}}$ although it would explain the negative inter- 
cept time of the travel-time curve of $\overline{\mathrm{P}}$ (table 3). The second part of the $\mathbf{P}$ group (phases marked e to $\mathrm{E}$ in table 3 ) and, still clearer, the corresponding part of the S group (phases in table 4) create the impression of waves traveling in a dispersive medium. Such phenomena would be expected if there is a lowvelocity layer at a depth of about $20 \mathrm{~km}$. as suggested by the author.

Revised average trace amplitudes for various $S$ waves in southern California earthquakes can be found from table 5 . The waves s ("direct $S$ ") and $\mathrm{Sn}$ have about seven times the amplitudes of the corresponding $P$ phases; the maximum in $\mathrm{S}$ has about five times the amplitudes of the maximum in $\mathrm{P}$. It is noteworthy that the values for $\overline{\mathbf{S}}$ in table 5 correspond within 0.1 to the corresponding values for the seismogram maximum on which Richter (1935) has based the magnitude scale. The difference in the trace amplitudes for $\mathrm{S}$ and $P$ is not necessarily an indication that the transverse waves receive more energy at the source than the $\mathrm{P}$ waves, since normally the periods of the $\mathrm{S}$ waves are greater than those for the $P$ waves, and since the ratio refers to the horizontal trace amplitudes, which have a different ratio to the actual ground motion in $\mathrm{S}$ and $\mathrm{P}$ waves. (For a more detailed discussion see Gutenberg, 1945, p. 305.)

\section{SUMMARY}

The reinterpretation of seismograms of earthquakes on the assumption that $P$ and $S$ start simultaneously results in the following wave velocities in southern California which fit the observed travel times and amplitudes of earthquakes as well as of blast records. The latter indicate that the velocity of longitudinal waves in the upper $5 \mathrm{~km}$. is about $5.8 \mathrm{~km} / \mathrm{sec}$, that at a depth of about $5 \mathrm{~km}$. it increases rather rapidly or suddenly to about $6.5 \mathrm{~km} / \mathrm{sec}$, and at a depth of about $11 \mathrm{~km}$. to 6.8 or $6.9 \mathrm{~km} / \mathrm{sec}$. Data from earthquakes lead to the conclusion that the average velocity between the source of earthquakes at a depth of about $16 \mathrm{~km}$. and the surface of the earth is about $V=6.35 \mathrm{~km} / \mathrm{sec}$. for longitudinal waves $(\mathrm{p})$ and about $v=3.67 \mathrm{~km} / \mathrm{sec}$. for transverse waves (s) $V / v=1.73$; the corresponding value of Poisson's ratio is near 0.25 . The amplitudes of $p$ indicate that at the depth of the focus the wave velocity decreases with depth. The amount of this decrease cannot be calculated without additional theoretical studies on the propagation of waves in such a structure. However, on the basis of the present investigation it seems unlikely that the minimum of the wave velocities at a depth of the order of $20 \mathrm{~km}$. is much below $6 \mathrm{~km} / \mathrm{sec}$. for $P$ and $31 / 2 \mathrm{~km} / \mathrm{sec}$. for $\mathrm{S}$. A sudden increase in velocity occurs at a depth of about $28 \mathrm{~km}$. and produces strong reflected waves; the corresponding refracted waves are less clear (which may be a consequence of the relatively small thickness of roughly two wave lengths of the layer) and indicate a velocity of about $7.1 \mathrm{~km} / \mathrm{sec}$. for the longitudinal waves and about $4.1 \mathrm{~km} / \mathrm{sec}$. for transverse waves in the layer below this discontinuity. Strong reflected and refracted waves are connected with the Mohoro- 
vičić discontinuity, which is at a depth of about $35 \mathrm{~km}$. in the coastal areas of southern California, but deeper under the mountain areas. The velocities below this discontinuity are 8.1 to $8.2 \mathrm{~km} / \mathrm{sec}$. and about $4.5 \mathrm{~km} / \mathrm{sec}$., respectively. There is no indication that there is a discontinuity between the Mohorovičic discontinuity and a depth of about $80 \mathrm{~km}$., and the rather long periods of Pn may be taken as confirmation. At distances greater than about $100 \mathrm{~km}$. the second part of the $\mathrm{P}$ and $\mathrm{S}$ groups consists of more or less continuous motion over a time interval increasing with distance. These waves seem to exhibit dispersion and to culminate in $\overline{\mathrm{P}}$ and $\overline{\mathrm{S}}$, respectively. They may correspond to surface waves traveling along a low-velocity channel.

\section{GUTENBERG, B.}

\section{REFERENCES}

1943. "Earthquakes and Structure in Southern California," Bull. Geol. Soc. Am., 54: 499-526.

1944a. "Travel Times of Principal P and S Phases over Small Distances in Southern California," Bull. Seism. Soc. Am., 34:13-32.

1944b. "Energy Ratio of Reflected and Refracted Seismic Waves," Bull. Seism. Soc. Am., 34:85-102.

1944c. "Reflected and Minor Phases in Records of Near-by Earthquakes in Southern California," Bull. Seism. Soc. Am., 34: 137-160.

1945a. "Variations in Physical Properties within the Earth's Crustal Layers," Am. Jour. Science, 243(A): 285-312.

1945b. "Amplitudes of P, PP, and S and Magnitude of Shallow Earthquakes," Bull. Seism. Soc. Am., 35: 57-69.

1950a. "Travel Times from Blasts in Southern California," Bull. Seism. Soc. Am., 41: 5-12 (1951).

1950b. "Structure of the Earth's Crust in the Continents," Science, 111:29-30.

Gutenberg, B., and C. F. Richter

1939. "On Seismic Waves (Fourth Paper)," Gerlands Beitr. z. Geophysik, 54: 94-136.

Gutenberg, B., H. O. Wood, and C. F. Richter

1933. "Re Suggestion by Dr. Harold Jeffreys Regarding P and Pg," Gerlands Beitr. z. Geophysik, 40: 97-98.

RichTer, C. F.

1935. "An Instrumental Earthquake Magnitude Scale," Bull. Seism. Soc. Am., 25:1-32

1950. "Velocities of P at Short Distances," Bull. Seism. Soc. Am., 40:281-289. 